\section{ACEing the MS test}

\section{By Lev Osherovich, Senior Writer}

A pair of studies by German and American researchers implicates the renin-angiotensin pathway as a key regulator of inflammation in the brain. ${ }^{1,2}$ The studies suggest that widely used hypertension drugs that antagonize the pathway could help treat multiple sclerosis. The challenge now is to work out MS-specific dosing protocols and find trial sponsors.

The renin-angiotensin system is a hormonal signaling pathway that works in the kidneys and blood vessels to control blood volume. Components of the pathway are well-characterized cardiovascular drug targets. Nine generic small molecule inhibitors of angiotensinconverting enzyme (ACE) and six angiotensin receptor blockers are on the market for hypertension and complications of myocardial infarction (MI). There is one direct renin inhibitor on the market for hypertension: Tekturna aliskiren from Novartis AG.

Components in the pathway have recently turned up as players in autoimmunity and neuroinflammation. ${ }^{3}$ Now, two papers published in the Proceedings of the National Academy of Sciences carry the observation forward and show that multiple drugs targeting the renin-angiotensin pathway also protect against autoimmune inflammation in a mouse model of MS.

The reports were from separate teams, one led by Lawrence Steinman, professor of immunology at Stanford University, and the other by Ralf Linker, attending physician in the Department of Neurology at Ruhr University Bochum.

\section{Angiotensin tamer}

Steinman said his team's study stemmed from hints that the reninangiotensin pathway has a role in inflammation triggered by autoimmune reactions. Last year, the team reported that a proteomic analysis of MS lesions showed higher levels of renin-angiotensin pathway proteins in diseased tissue than in healthy controls. ${ }^{4}$

In the PNAS study, Steinman's team used immunohistochemistry to show that spinal cord tissue from MS patients had higher levels of angiotensin II type 1 receptor (AGTR1; AT $\mathrm{R}_{1}$ ) than healthy tissue.

"We found the footprint of the renin-angiotensin system in MS plaques, so the next obvious step was to try to reverse the disease in mouse models" using inhibitors of the pathway, Steinman told SciBX.

In a murine experimental autoimmune encephalomyelitis (EAE) model of MS, the generic ACE inhibitor lisinopril lowered histological and behavioral signs of inflammation compared with mock treatment. The team obtained similar results with Atacand candesartan cilexetil, an AGTR1 inhibitor marketed by AstraZeneca plc and
Takeda Pharmaceutical Co. Ltd. for cardiovascular and ophthalmic indications.

Steinman's results are in line with those from Linker's team, which tested the effect of several renin-angiotensin pathway inhibitors in another mouse EAE model.

"We found that several components of the renin-angiotensin system are expressed in the MS model we used and could be modulated to affect the course of the disease," said Linker. "This includes blocking renin and the angiotensin receptor."

Indeed, Novartis' Tekturna, the generic ACE inhibitor enalapril and Merck \& Co. Inc.'s Cozaar losartan AGTR1 antagonist protected mice against EAE. Treated mice had less severe neurological defects and fewer histological markers of inflammation than untreated mice.

"It's quite surprising to see the magnitude of the effect in a rigorous model of autoimmune CNS injury, as well as the similarity between the two papers," said Thomas Coffman, professor of medicine at Duke University. In March, Coffman's team discovered a role for the renin-angiotensin system in systemic lupus erythematosus (SLE). ${ }^{5}$

Blocking the pathway "really does seem to modify the nature of the autoimmune damage," said Coffman. "However, there's some disagreement between the two papers about which cells are modified" by the pathway.

Linker's team detected increased levels of AGTR1 in innate immune cells such as macrophages and dendritic cells (DCs) at the sites of inflammation. Thus, he suspects these innate immune cells may be the targets of renin-angiotensin signaling.

On the other hand, Steinman's team found that blocking the pathway increased levels of $\mathrm{T}_{\text {reg }}$ cells, components of the adaptive immune system that turn down inflammation.

Coffman noted that AGTR1 is likely to be present in many cell types and that renin-angiotensin signaling could thus occur in both innate and adaptive immune cells.

Linker agreed. "The renin-angiotensin pathway is not a one-way road but instead has many branches," he told SciBX.

\section{Proof in man}

Regardless of the precise mechanism, Linker, Steinman and Coffman agree that renin-angiotensin inhibitors are ready for testing in humans as treatments for MS and other autoimmune diseases such as lupus.

"The next step is a proof-of-concept trial in man," said Steinman.

Linker said working out MS-specific dosing regimens for ACE inhibitors and AGTR1 antagonists in humans is a priority.

"In EAE, you can dose much higher than in humans," said Linker. "We used doses that significantly reduced blood pressure in mice, so people may not tolerate such high doses."

On the plus side, he said, "there are 80 million people taking these drugs for hypertension without safety issues.” 
It may be possible to detect a benefit to taking ACE inhibitors in a retrospective study of MS patients, but Steinman noted that the heterogeneity of MS symptoms and difficulties with access to medical records make a prospective study much more attractive.

"These are strong, solid findings," said Timothy Coetzee, president of Fast Forward LLC, the venture investment arm of the National Multiple Sclerosis Society. "The next stage is asking whether putting these drugs into humans will modify the disease."

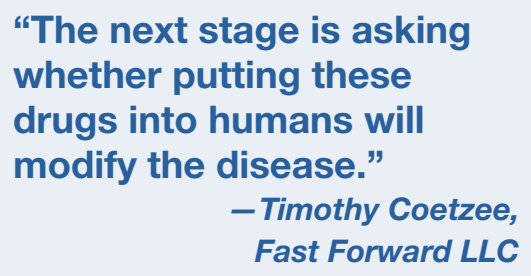

In the private sector, Coetzee thinks that generic drug makers specializing in the repurposing of generics could potentially stand to gain from a new market for renin-angiotensin pathway antagonists. "The critical issue comes down to finding the dosing regimen that works and to then ensure that there's some potential profitability," he said.

Coetzee added that patenting the use of older generic compounds to treat MS would be essential to drum up industry interest.

Steinman has filed a patent on his team's discoveries and is seeking to out-license the IP. Linker did not patent his findings.

Osherovich, L. SciBX 2(35); doi:10.1038/scibx.2009.1329

Published online Sept. 10, 2009

\section{REFERENCES}

1. Platten, M. et al. Proc. Natl. Acad. Sci. USA; published online Aug. 19, 2009; doi:10.1073/pnas.0903958106

Contact: Lawrence Steinman, Stanford University, Stanford, Calif. e-mail: steinman@stanford.edu

Contact: Michael Platten, University Hospital Heidelberg, Heidelberg, Germany e-mail: michael.platten@med.-uni-heidelberg.de

2. Stegbauer, J. et al. Proc. Natl. Acad. Sci. USA; published online Aug. 19, 2009; doi:10.1073/pnas.0903602106

Contact: Ralf A. Linker, Ruhr University Bochum, Bochum, Germany e-mail: ralf.linker@rub.de

3. Tyndall, A. et al. Rheumatology (Oxford) 48, 49-53 (2009)

4. Han, M.H. et al. Nature 451, 1076-1081 (2008)

5. Crowley, S. et al. J. Clin. Invest. 119, 943-953 (2009)

COMPANIES AND INSTITUTIONS MENTIONED

AstraZeneca plc (LSE:AZN; NYSE:AZN), London, U.K.

Duke University, Durham, N.C.

Fast Forward LLC, New York, N.Y.

Merck \& Co. Inc. (NYSE:MRK), Whitehouse Station, N.J.

National Institutes of Health, Bethesda, Md.

National Institute of Neurological Disorders and Stroke, Bethesda, Md.

National Multiple Sclerosis Society, New York, N.Y.

Novartis AG (NYSE:NVS; SIX:NOVN), Basel, Switzerland

Ruhr University Bochum, Bochum, Germany

Stanford University, Stanford, Calif.

Takeda Pharmaceutical Co. Ltd. (Tokyo:4502), Osaka, Japan 